\title{
Urgences
}

\section{Journal d'un quêteux à cheval}

\section{Rock Plante}

Numéro 20, mai 1988

Appellation contrôlée

URI : https://id.erudit.org/iderudit/025476ar

DOI : https://doi.org/10.7202/025476ar

Aller au sommaire du numéro

Éditeur(s)

Urgences

ISSN

0226-9554 (imprimé)

1927-3924 (numérique)

Découvrir la revue

Citer ce document

Plante, R. (1988). Journal d'un quêteux à cheval. Urgences, (20), 33-34.

https://doi.org/10.7202/025476ar

Ce document est protégé par la loi sur le droit d'auteur. L'utilisation des services d'Érudit (y compris la reproduction) est assujettie à sa politique d'utilisation que vous pouvez consulter en ligne.

https://apropos.erudit.org/fr/usagers/politique-dutilisation/
Cet article est diffusé et préservé par Érudit.

Érudit est un consortium interuniversitaire sans but lucratif composé de l’Université de Montréal, l'Université Laval et l'Université du Québec à Montréal. Il a pour mission la promotion et la valorisation de la recherche. https://www.erudit.org/fr/ 


\section{ROCK PLANTE \\ Journal d'un quêteux à cheval}

le vendredi 13 février 1988

07.59: J'étais en train de démonter le délicat mécanisme électropneumatique d'une machine électronique à points d'arrêts lorsque je fus mandé au bureau. "C'est-une-communication-téléphoniqueurgente-un-interurbain-Québec-la-ville», de me souffler à l'oreille le patron. Moi, quand c'est un téléphone urgent, je prends le temps de m'essuyer les mains, car l'huile filante, ça laisse de vilains cernes sur le combiné, pis la secrétaire aime pas ça. Je m'attendais à Réjean Tremblay, à tout, sauf à un dénommé Jean-Pierre Guédille-Au-Nez qui $m$ 'invite entre deux invectives à me gosser une cheville de cèdre pis de me la mettre... d'en travers le gorgotton, tellement je pue de la gueule et que et que ... Je raccroche. Il est inutile de discuter avec les Témoins de Jéhovah, les avocats... pis les Ti-Pit de Beauport. De plus, je suis un homme sans quantité, un quêteux à cheval sur lequel il est inutile de perdre son temps. POTIUS VIR BONUS, DICENDI PERITUS pis VERITAS ODIUM PARIT.

09.22: Pages roses du dictionnaire Larousse: «Plutôt un homme de bien qui sait parler» pis "La franchise engendre la haine». DIXIT/

09.23: Je vais méditer ça à la pause-café pendant que mon compagnon d'infortune m'entretiendra de la défaite des Sadiques aux mains sales des Moins-Que-Rien.

09.24: Je vais à la buvette. Onze minutes avant la pause-café. Le patron surveille les gars qui font trop de plancher juste avant. Ça fait rien. Pendant que je brasse de l'air, y a pas de brasse-camarade.

09.30: Je vais à la toilette. Cinq minutes avant la pause-café. Le miroir est ben sale pis je pense à la préface pédagogique que je demanderai bien un jour à François Charrue pour mon anthologie sur les terres à foin sans fin. Celui-là, c'est un prolétaire en l'air qui a mal tourné dans les hosties pour son insignifiant intime, infecte nature de la nature. Mais cé un ben bon pouète, paraît-il. Cé François Berbère (le vrai) qui me l'a dit en... enenen... j'm'en souviens pus!

09.35: Je bois un café noir. La fumée d'une cigarette me rappelle la théorie mathématique des catastrophes. Tout se détruit. Tout se réduit. Un dinosaure dévore un herbivore dans mon lointain Crétacé. Jean-Pierre Guédille-Au-Nez mord son sabord et enfile sa Marie- 
Chantale. Les singes ont la grippe et je m'ennuie de tous les livres que je détruirai.

09.50: C'est le jour de mon anniversaire! Mon éditeur m'a promis pour aujourd'hui un chèque pour tous les droits d'auteur impayés depuis quinze ans. J'ai hâte de recevoir mon courrier! C'est qu'il est fiable mon éditeur. C'est un chic type qui paie trente-cinq mille dollars de droits d'auteur à une professeure d'université qui n'en a pas besoin pour manger, tandis que je me ronge les ongles à savoir si la p'tite dernière va avoir les moyens d'y aller... Mais c'est quand même un chic type. Un mécène.

09.59: Je suis congédié. 